\title{
A TRANSGRESSÃO DO DIREITO FUNDAMENTAL À EDUCAÇÃO E OS RETROCESSOS NO ENSINO CONSEQUÊNCIA DO COVID 19: DESAFIOS DA EDUCAÇÃO NO PÓS-PANDEMIA
}

\author{
MURIANA CARRILHO BERNARDINELI ${ }^{1}$, CAMILA SANCHEZ ALEIXO DE \\ ALMEIDA $^{2}$
}

\begin{abstract}
${ }^{1}$ Doutoranda em Função Social do Direito pela Faculdade Autônoma de Direito (FADISP). Mestre em Ciências Jurídicas pela Centro Universitário de Maringá (Unicesumar). Especialista em Direito do Trabalho e Previdenciário pelo Instituto de Direito e Cidadania (IDCC) em parceria com Universidade Estadual do Norte do Paraná (UENP). Bacharel em Direito pela Universidade Estadual de Maringá (UEM). Docente do curso de Graduação em Direito da Faculdade Alvorada em Maringá - PR. Advogada. ${ }^{2}$ Especialista em Direito do Trabalho e Previdenciário pelo Instituto de Direito e Cidadania (IDCC) em parceria com Universidade Estadual do Norte do Paraná (UENP). Bacharel em Direito pela Universidade Estadual de Maringá-PR (UEM). Advogada.
\end{abstract}

\section{RESUMO}

A presente pesquisa tem como objetivo levantar hipóteses sobre como ficará a educação após a pandemia do Covid-19. É importante destacar que o direito à educação é um direito fundamental, previsto no capítulo dos direitos sociais, na Constituição Federal de 1988. Historicamente, os direitos sociais surgiram diante da percepção da sociedade de que era preciso a atuação positiva por parte do Estado para concretizar esses direitos, de modo a garantir o acesso democrático a todos os cidadãos. Esses direitos são classificados como direitos fundamentais de segunda geração. No contexto atual da pandemia, as instituições de ensino tiveram que se adaptar para que os alunos não tivessem seu direito à educação tolhido ou diminuído, adotando como solução, em muitos casos, o ensino remoto. O Estado, por sua vez, também teve que atuar de modo a regularizar essa situação por meio da publicação de normas de caráter temporário. Porém, o cerne da questão que assola o país, não é jurídica e/ou técnica, mas sim a evidente desigualdade social que reflete diretamente nas possíveis consequências que a pandemia irá ocasionar no sistema educacional brasileiro. O contexto atual evidencia que, após a Covid-19, há uma tendência de alta na evasão escolar e no desencadeamento de problemas psicológicos tanto em alunos como em professores. Além disso, a pandemia veio para acelerar uma tendência mercadológica, adotada por parte das instituições de ensino, que é o oferecimento dos cursos à distância em detrimento do modelo presencial. Por fim, menciona-se, ainda, que foram utilizados, para elaboração deste artigo, o método histórico e indutivo, pautando-se em documentos físicos e eletrônicos.

Palavras-Chave: Direito Fundamental; Educação; Ensino Remoto; Pandemia. 


\title{
THE TRANSGRESSION OF THE FUNDAMENTAL RIGHT TO EDUCATION AND THE BACKGROUNDS IN TEACHING CONSEQUENCE OF COVID 19: CHALLENGES OF EDUCATION IN THE POST PANDEMIC
}

\begin{abstract}
This research aims to raise hypotheses about what education will look like after the Covid-19 pandemic. It is important to highlight that the right to education is a fundamental right, provided for in the chapter on social rights, in the Federal Constitution of 1988. Historically, social rights emerged in the face of society's perception that positive action by the State was necessary to achieve these rights in order to guarantee democratic access for all citizens. They are classified as second generation fundamental rights. In the current context of the pandemic, educational institutions had to adapt so that students did not have their right to education curtailed or diminished, adopting remote teaching as a solution in many cases. The State, in turn, also had to act in order to regularize this situation through the publication of temporary rules. However, the heart of the issue that plagues the country is not legal and / or technical, but the evident social inequality that directly reflects on the possible consequences that the pandemic will cause in the Brazilian educational system. The current context shows that, after Covid-19, there is an upward trend in school dropout and the triggering of psychological problems in both students and teachers. In addition, the pandemic came to accelerate a market trend, adopted by educational institutions, which is the provision of distance learning courses to the detriment of the face-to-face model. Finally, mention is also made of the use of the historical and inductive method for this article, based on physical and electronic documents.
\end{abstract}

Key-Words: Fundamental Right; Education; Remote Teaching; Pandemic.

\section{INTRODUÇÃO}

O presente artigo tem como objetivo analisar os impactos da atual pandemia no sistema educacional brasileiro, com vistas a levantar hipóteses sobre como ficará a educação no cenário do pós-Covid-19.

O conteúdo perquirido neste estudo justifica-se, pois é sabido ser a educação um direito fundamental; no entanto, necessário se faz a sua efetivação cotidianamente, o que sofreu ainda maiores prejuízos com pandemia do Covid-19, pois a conversão drástica para o ensino remoto dificultou o acesso duitos estudantes ao conteúdo 
ministrado diariamente nas instituições de ensino, promovendo nítido retrocesso ao ensino e gerando dúvida sobre qual o futuro da educação no Brasil.

Objetiva-se, nesta pesquisa, apresentar algumas normas jurídicas que perpassam o ensino remoto, de modo a demonstrar se há respaldo para as instituições oferecerem o ensino a distância e, ao mesmo tempo, pretende-se investigar como esta forma de ensino tem funcionado no Brasil; para então, levantar hipóteses de como ficará a educação póspandemia, inclusive no que diz respeito às normativas temporárias criadas.

Como resultados, almeja-se encontrar soluções ao atual cenário educacional e, consequentemente, melhorias para o futuro do ensino no Brasil, o qual está eminentemente relacionado às desigualdades sociais vivenciadas, pois, para que o país possa voltar a crescer, o ensino precisa ser prioridade da nação.

Menciona-se que esta pesquisa é teórica e encontra-se baseada na doutrina e atual realidade social, possuindo como intuito analisar a realidade da educação no atual contexto da pandemia, para assim fazer um paralelo de como ficará o ensino no pósCovid.

Para tanto, foram utilizados o método histórico com o objetivo de analisar o direito fundamental à educação. Utilizou-se ainda de referências teóricas e revisão de literatura de obras e documentos, pautando-se em fontes documentais de livros, artigos, revistas especializadas, tanto em meios físicos como eletrônicos.

O primeiro tópico destina-se a fazer um breve estudo sobre o direito fundamental à educação e sobre como as instituições de ensino estão fazendo para assegurar o acesso ao ensino, respeitando o isolamento social. Em sequência, no segundo capítulo, serão abordadas as normas jurídicas exaradas pelo Poder Público neste período, inclusive as de caráter temporário, buscando adequar-se ao novo cenário na pandemia.

O terceiro tópico tem como objetivo descrever o impacto da pandemia no sistema educacional brasileiro e averiguar se a desigualdade social que assola o país, pode, de alguma forma, influenciar o atual cenário da educação. Para, posteriormente, no quarto capítulo, levantar as possíveis implicações que a pandemia irá provocar no sistema educacional brasileiro, buscando dados, estudos e opiniões de especialistas sobre o cenário da educação no Pós-Covid. 
Por fim, no último capítulo, pretende-se apontar possível solução que vise melhorar o sistema educacional brasileiro, com vistas a preservar e dar efetividade ao direito fundamental da educação, ressaltando a necessidade de valorização do profissional da educação, assim como abordando uma proposta que vem sendo discutida por especialistas, qual seja, ensino híbrido como proposta educacional, analisando sobre suas vantagens e obstáculos sobre sua aplicabilidade.

\section{A EDUCAÇÃO COMO DIREITO FUNDAMENTAL}

Em todo o mundo, milhões de crianças e adolescentes tiveram o direito à educação suspenso ou limitado como medida de prevenção contra a pandemia do Covid-19. Muitas instituições de ensino optaram por adotar a forma remota de ensino e, por conta disso, algumas normativas foram expedidas durante esse período da pandemia, justamente para regularizar o ensino a distância. Ocorre que, no Brasil, as dificuldades vão muito além da questão jurídica/técnica do assunto, perpassando questões sociais que evidenciam ainda mais a desigualdade que assola o país.

Pois bem, é dificultoso desvencilhar a tentativa da oferta do ensino a distância, pelas diversas instituições brasileiras públicas e privadas, da realidade social que se vive no país.

Inicialmente, necessário delimitar e transcorrer brevemente sobre o direito a educação. No ordenamento jurídico brasileiro, o direito à educação é assegurado constitucionalmente como um direito fundamental, visto que está expresso no art. $6^{\circ}$ da Constituição Federal de 1988, no capítulo destinado aos Direitos Sociais, no Título II dos Direitos Fundamentais (BRASIL, 1988).

Conforme sustenta José Afonso da Silva, o qualificativo "fundamentais" indica que tais direitos são tão básicos e essenciais, que, sem eles, a pessoa humana não tem condições de se realizar, de conviver, ou até mesmo de sobreviver (SILVA, 2009, 178).

Para George Marmelstein, os direitos fundamentais:

São normas jurídicas, intimamente ligadas à idéia de dignidade da pessoa humana e de limitação do poder, positivadas no plano constitucional de determinado Estado Democrático de Direito, que, por sua importância axiológica, fundamentam e legitimam todo o ordenamento jurídico (MARMELSTEIN, 2011, p. 20). 
Portanto, tratam-se de direitos que irão eivar todo e qualquer disposição legal constante no ordenamento jurídico, apresentando-se como um direito que deve ser tutelado em todas as esferas da vida humana.

Robert Alexy resume bem os traços que definem tais direitos, por ele denominados de "direitos humanos fundamentais". São eles: "1) ser vinculado diretamente à dignidade da pessoa humana; 2) portanto, concernir a todos os seres humanos; 3) ter valor moral; 4) ser suscetível de garantia pelo direito; 5) pesar de modo capital para a vida de cada um" (ALEXY, 1999, p. 206).

Pois bem, os direitos fundamentais são divididos doutrinariamente em três gerações, há doutrinadores ainda que defendem uma quarta geração. Desse modo, apenas com intuito elucidativo, serão feitas breves considerações sobre as gerações com enfoque na segunda geração, visto que é nesta que se encontra o direito social à educação.

Historicamente, os direitos de primeira geração, fundamentados na liberdade, composta pelos direitos civis e políticos, remonta aos séculos XVII e XVIII, quando o Estado Absoluto cedeu lugar ao Estado Liberal de Direito. Os direitos individuais eram oponíveis ao Estado Absolutista, de modo a impedir a interferência estatal na vida privada dos cidadãos. Ao Estado liberal caberia apenas o dever de respeitar e assegurar os direitos fundamentais, especialmente, os direitos à vida, à propriedade, à liberdade e à igualdade formal (LEITE, 2011, p. 59).

O Estado anterior, absoluto, era marcado pela intolerância religiosa, pela ausência de garantias processuais, pela ausência de liberdade econômica, liberdade política e liberdade de expressão. A insatisfação da sociedade com a opressão fez despontar as revoluções liberais, o que resultou na elaboração das Declarações de Direitos, entre as quais merecem destaque a Declaração Universal dos Direitos do Homem e do Cidadão, de 1789, fruto da Revolução Francesa, e a Declaração da Virgínia, de 1776, decorrente da Revolução Americana. (MARMELSTEIN, 2011, p. 44-45).

Segundo Manoel Gonçalves Ferreira Filho, os direitos de primeira dimensão são “direitos subjetivos oponíveis ao Estado" ou, como alguns preferem, são "poderes de agir reconhecidos e protegidos pela ordem jurídica a todos os seres humanos", sendo 
caracterizados como abstratos; imprescritíveis; inalienáveis; individuais; universais (FERREIRA FILHO, 2011, p. 46, 40-41).

Nesse diapasão, o Estado atua apenas no aspecto negativo, limitando-se a respeitar e assegurar as liberdades individuais, especialmente o direito à vida e à propriedade.

Porém, o Estado liberal, atrelado ao impacto da industrialização, fez emergir graves problemas sociais e econômicos e, desse modo, consolidou a convicção de que, para o efetivo desfrute dos direitos individuais, seria necessário que o Estado garantisse condições mínimas de existência para cada indivíduo.

Assim, ao contrário do que antes se defendia, nasce o que se denomina Estado do bem-estar social (Welfare State), um novo modelo político oposto ao Estado Liberal, que tem como objetivo enfrentar os extremos desníveis sociais por meio de uma política intervencionista, que busca garantir as condições básicas para uma vida digna.

Com o advento do denominado Estado Social, cuja característica dominante é a inserção de direitos sociais nas constituições, surge a teoria do status positivo, segundo a qual o Estado, além de proteger os direitos individuais, deve atuar positivamente no sentido de concretizar os direitos sociais, seja intervindo nas relações entre particulares (dirigismo contratual), seja atuando diretamente por meio de prestações estatais positivas (LEITE, 2011, p. 60).

De acordo com Manoel Gonçalves Ferreira Filho, os direitos sociais são direitos subjetivos, poderes de exigir prestação concreta por parte do Estado, ou seja, são direitos de crédito (FERREIRA FILHO, 2011, p. 67-68). Por isso, George Marmelstein sublinha que:

(...) os direitos de segunda geração funcionam como uma alavanca ou uma catapulta capaz de proporcionar o desenvolvimento do ser humano, fornecendo-lhe as condições básicas para gozar, de forma efetiva, a tão necessária liberdade (MARMELSTEIN, 2011, p. 53).

O indivíduo, então, passa a exigir do Estado, além do dever de abstenção nos seus direitos de primeira geração, uma atuação positiva, a fim de assegurar diretamente a realização dos direitos de segunda dimensão, justamente onde se encontra o direito social à educação. 
A terceira dimensão, fundamentada na fraternidade (fraternité), é caracterizada pelos direitos de solidariedade, que englobam, principalmente, o direito à paz, o direito ao desenvolvimento, o direito ao meio ambiente, o direito de comunicação e o direito de propriedade sobre o patrimônio comum da humanidade.

Atualmente, há autores que defendem a existência de novas dimensões de diretos, em decorrência da globalização, dos avanços tecnológicos, das descobertas genéticas, entre outros fatores.

Pois bem, percebe-se, por essa breve exposição, que os direitos fundamentais de segunda dimensão se consolidaram no momento em que foi necessária a atuação por parte do Estado para garantir que os direitos sociais não fossem tolhidos por interesses econômicos e mercantis.

Permanece, assim, a recalcitrância do Estado no cumprimento e efetivação dos direitos fundamentais aos cidadãos mais necessitados. Tal fato não se coaduna com a ideia de que a "ordem jurídica constitucional para a construção de uma sociedade verdadeiramente livre justa e solidária, que se desenvolva, erradicando a pobreza e a marginalização, reduzindo as desigualdades sociais e regionais” (CARVALHO, 2015, p. 243).

A CF/88 proclama que a educação é direito de todos e dever do Estado e da família, com vistas a alcançar os seguintes objetivos: pleno desenvolvimento da pessoa, preparo para o exercício da cidadania e sua qualificação para o trabalho, conforme se verifica pelo art. 205 , da $\mathrm{CF}$, in verbis:

Art. 205. A educação, direito de todos e dever do Estado e da família, será promovida e incentivada com a colaboração da sociedade, visando ao pleno desenvolvimento da pessoa, seu preparo para o exercício da cidadania e sua qualificação para o trabalho (BRASIL, 1988, on-line).

Também informa que o ensino terá como princípios: igualdade de acesso, gestão democrática do ensino público, garantia de padrão de qualidade, dentre outros listados no art. 206 da CF/1988, in verbis:

Art. 206. O ensino será ministrado com base nos seguintes princípios:

I - igualdade de condições para o acesso e permanência na escola;

II - liberdade de aprender, ensinar, pesquisar e divulgar o pensamento, a arte e o saber; 


\begin{abstract}
III - pluralismo de idéias e de concepções pedagógicas, e coexistência de instituições públicas e privadas de ensino; IV - gratuidade do ensino público em estabelecimentos oficiais;

V - valorização dos profissionais da educação escolar, garantidos, na forma da lei, planos de carreira, com ingresso exclusivamente por concurso público de provas e títulos, aos das redes públicas;

VI - gestão democrática do ensino público, na forma da lei;

VII - garantia de padrão de qualidade.

VIII - piso salarial profissional nacional para os profissionais da educação escolar pública, nos termos de lei federal trabalho (BRASIL, 1988, on-line).
\end{abstract}

A Carta Magna também define que a União, os Estados, o Distrito Federal e os Municípios organizarão em regime de colaboração o sistema de ensino. Cabendo a União organizar o sistema federal e dos territórios e garantir a equalização de oportunidades educacionais e padrão mínimo de qualidade do ensino mediante assistência técnica e financeira aos Estados, Distrito Federal e Municípios, como descreve o art. 211, CF, infra transcrito:

\footnotetext{
211. A União, os Estados, o Distrito Federal e os Municípios organizarão em regime de colaboração seus sistemas de ensino.

$\S 1^{\circ}$ A União organizará o sistema federal de ensino e o dos Territórios, financiará as instituições de ensino públicas federais e exercerá, em matéria educacional, função redistributiva e supletiva, de forma a garantir equalização de oportunidades educacionais e padrão mínimo de qualidade do ensino mediante assistência técnica e financeira aos Estados, ao Distrito Federal e aos Municípios (BRASIL, 1988, on-line).
}

Assim sendo, a interação e a colaboração mútua se faz necessária como forma de buscar melhor qualidade e condições de ensino no Brasil, de modo que a União, os Estados, o Distrito Federal e os Municípios devem caminhar no mesmo sentido.

Assim, o direito a educação, como típico direito social, obriga o Estado a oferecer o acesso a todos interessados, principalmente àqueles que não possuem condições de arcar com o custo de uma educação particular. Os direitos sociais ocupamse, prioritariamente, dos cidadãos mais carentes (TAVARES, 2009, p. 7).

No atual cenário da pandemia, as instituições de ensino, juntamente com o Poder Público, estão buscando alternativas para efetivar o direito à educação e, ao mesmo tempo, respeitar as recomendações dos órgãos de saúde, no que diz respeito ao isolamento social.

Diante desse cenário, a educação migrou, transitoriamente, do modelo presencial para o ensino remoto. Os atores sociais tiveram que se adaptar à nova realidade, 
inclusive o Poder Público que rapidamente buscou regularizar juridicamente essa situação, conforme será analisado no tópico abaixo.

\section{O NOVO CENÁRIO NA PANDEMIA: ENSINO REMOTO E AS NORMAS JURÍDICAS}

De forma abrupta, a pandemia trouxe um novo cenário em praticamente todas as esferas da vida humana, de modo que a população se viu obrigada ao isolamento social como maneira de diminuir a contaminação, assim os mais variados estabelecimentos comerciais tiveram que fechar suas portas, assim como as instituições de ensino também o fizeram.

A pandemia da Covid-19 fechou escolas em 165 países, deixando 87\% de todos os alunos do mundo sem aulas, conforme dados da Organização das Nações Unidas (JOLIE; AZOULAY, 2020). Em relação ao Brasil, de acordo com dados da Unesco, agência da ONU para educação, 52 milhões de estudantes brasileiros estão fora das salas de aulas. Os especialistas defendem que a pandemia irá alterar o modelo educacional vigente nos dias de hoje (CERIONI, 2020).

A alternativa que vem sendo adotada pelas instituições de ensino dos diversos países e também pelo Brasil para que não haja a interrupção do processo educativo é o ensino remoto, já que pode ser feito a distância, através dos meios eletrônicos que conectam alunos, escolas e professores, respeitando, desse modo, o distanciamento social.

Assim, importante discorrer sobre as normas jurídicas, emanadas pelo Poder Público, que regulam o ensino a distância e permitem que as instituições adotem esse modelo de ensino.

A Lei de Diretrizes e Bases da Educação Nacional (Lei 9.394/1996) é a legislação que regulamenta o sistema educacional, público e privado, do Brasil. A educação brasileira é dividida em dois níveis: educação básica, formada pela educação infantil, ensino fundamental e ensino médio; e educação superior. O artigo 21 da referida lei descreve essa dicotomia, conforme se verifica in verbis:

Art. 21. A educação escolar compõe-se de: 
I - educação básica, formada pela educação infantil, ensino fundamental e ensino médio;

II - educação superior (BRASIL, 1996, on-line).

A LDB 9.394/96, em resumo, reafirma o direito à educação, garantido pela Constituição Federal, assim, estabelece os princípios da educação e os deveres do Estado em relação à educação escolar pública, define as responsabilidades, em regime de colaboração, entre a União, os Estados, o Distrito Federal e os Municípios e também, disciplina algumas normas sobre a formação dos profissionais da educação (BRASIL, 1996, on-line).

Em relação ao ensino à distância, o artigo 80 da LDB 9.394/96 prevê que cabe ao Poder Público incentivar o desenvolvimento e a veiculação de programas de ensino à distância, em todos os níveis e modalidades de ensino e de educação continuada, nos termos transcritos: "Art. 80. O Poder Público incentivará o desenvolvimento e a veiculação de programas de ensino a distância, em todos os níveis e modalidades de ensino, e de educação continuada.” (BRASIL, 1996, on-line).

O Decreto $n^{\circ} 9.057$ que regulamenta o artigo 80 da LDB 9.394/96, foi publicado no ano de 2017, portanto, é uma norma jurídica recente e que demonstra como o ensino a distância está se destacando como modalidade de ensino no país (BRASIL, 2017).

$\mathrm{O}$ artigo $8^{\circ}$ do decreto discrimina a educação à distância nos seguintes níveis e modalidades: I- Ensino fundamental; II- Ensino médio; III- Educação profissional técnica de nível médio; IV- Educação de jovens e adultos; V- Educação especial. O dispositivo é específico ao estipular a competência para as autoridades estaduais, municipais e distritais autorizarem os cursos e funcionamento das instituições de ensino na modalidade à distância (BRASIL, 2017).

Em relação à educação fundamental, o ensino a distância somente pode ser adotado em situações emergenciais, conforme dispõe o artigo 32, §4 da LDB 9.394/96: “§ $4^{\circ} \mathrm{O}$ ensino fundamental será presencial, sendo o ensino a distância utilizado como complementação da aprendizagem ou em situações emergenciais" (BRASIL, 1996, online).

No que diz respeito ao ensino médio, a legislação autoriza o ensino a distância, desde que observados alguns requisitos, como se observa no artigo $\$ 11$ do art. 36, infra transcrito: 
$\S$ 11. Para efeito de cumprimento das exigências curriculares do ensino médio, os sistemas de ensino poderão reconhecer competências e firmar convênios com instituições de educação a distância com notório reconhecimento, mediante as seguintes formas de comprovação:

I - demonstração prática;

II - experiência de trabalho supervisionado ou outra experiência adquirida fora do ambiente escolar;

III - atividades de educação técnica oferecidas em outras instituições de ensino credenciadas;

IV - cursos oferecidos por centros ou programas ocupacionais;

$\mathrm{V}$ - estudos realizados em instituições de ensino nacionais ou estrangeiras;

VI - cursos realizados por meio de educação a distância ou educação presencial mediada por tecnologias (BRASIL, 1996, on-line).

O Ministério da Educação, observando o padrão adotado em todo mundo neste período de pandemia, publicou quatro portarias, visando regularizar o ensino remoto.

As duas primeiras Portarias de $n^{\circ} 343 / 2020$ e 345/2020 foram expedidas em março de 2020 e autorizaram a substituição das disciplinas presenciais, em andamento, por aulas que utilizassem meios e tecnologias de informação e comunicação, pelo prazo de 30 dias. As instituições que, por ventura, fizessem a substituição, deveriam comunicar ao Ministério da Educação em até 15 dias (BRASIL, 2020).

No caso das instituições de ensino superior não aderirem ao sistema educacional à distância, previu-se a possibilidade, de modo alternativo, da suspensão das atividades acadêmicas pelo mesmo período. Outra possibilidade regulamentada pela portaria foi a possibilidade de alterar a o calendário de férias, desde que observados os dias letivos e horas-aula (BRASIL, 2020).

No dia 16 de abril, foi publicada outra Portaria do Ministério da Educação (MEC) n. 473/2020, prorrogando a autorização para as instituições de ensino substituírem as disciplinas presenciais pelo ensino remoto por mais 30 dias.

Por fim, o MEC expediu a Portaria de $n^{\circ} 544 / 2020$, em 16 de Junho de 2020, que revogou as Portarias de $n^{\circ}$ 343/2020, 345/2020 e 473/2020. Mas, apesar de revogar as portarias anteriores, tem o mesmo viés de autorizar a substituição das aulas presenciais por aulas em meios digitais. A Portaria previu que a substituição poderá se estender até o dia 31 de dezembro de 2020 , conforme se verifica no art. $1^{\circ}, \S 1^{\circ}$, in verbis:

Art. $1^{\circ}$ Autorizar, em caráter excepcional, a substituição das disciplinas presenciais, em cursos regularmente autorizados, por atividades letivas que utilizem recursos educacionais digitais, tecnologias de informação e comunicação ou outros meios convencionais, por instituição de educação 
superior integrante do sistema federal de ensino, de que trata o art. $2^{\circ}$ do Decreto $n^{\circ} 9.235$, de 15 de dezembro de 2017.

$\S 1^{\circ} \mathrm{O}$ período de autorização de que trata o caput se estende até 31 de dezembro de 2020 (BRASIL, 2020).

Do mesmo modo das portarias anteriores, ficou sob a responsabilidade das instituições de ensino comunicar ao Ministério da Educação-MEC sobre a opção pela substituição das atividades letivas pelo sistema remoto, mediante ofício, no prazo de 15 dias. Ademais, a portaria também previu a possibilidade das instituições de educação superior suspenderem as atividades acadêmicas presenciais pelo mesmo prazo.

Neste caso em que há opção pela suspensão das atividades, essas deverão ser integralmente repostas para fins de cumprimento da carga horária dos cursos, conforme legislação em vigor.

Convém destacar que o art. $1^{\text {o }}$ do Decreto 9.057/2017 define educação à distância como a modalidade educacional em que há utilização de meios e tecnologias de informação e comunicação, com pessoal qualificado e políticas de acesso, além de acompanhamento e avaliações compatíveis (BRASIL, 2017).

Ou seja, não basta a oferta do ensino remoto, o que deve também ser disponibilizado para uma educação de qualidade são professores capacitados e, principalmente, políticas de acesso a todos os estudantes. O Brasil vem enfrentando dificuldades neste último ponto, principalmente em virtude das desigualdades que assolam o Brasil, como se verificará a seguir.

\section{AS DIFICULDADES DO ENSINO REMOTO NO CONTEXTO SOCIAL BRASILEIRO}

Inicialmente, destaca-se que, no Brasil, há uma grande diferença entre as instituições privadas e públicas de ensino. Há quem defenda que a pandemia escancarou a desigualdade social existente no país.

Nos dizeres do professor Boaventura de Souza Santos: “A quarentena não só torna mais visíveis, como reforça a injustiça, a discriminação, a exclusão social e o sofrimento injusto que eles provocam" (SANTOS, 2020, p. 22).

As instituições de ensino privada estão enfrentando, com um pouco mais de tranquilidade, este momento, pois, via de regra, além de contarem com recurso humano, contam acima de tudo com meios eletrônicos suficientes para atenderem a demanda de 
seus alunos, os quais, por sua vez, na maioria dos casos, também possuem todo o aparato necessário para acessar as aulas: tablet, computador, além de uma internet de qualidade.

Ademais, o contexto social em que esses alunos estão inseridos estimula o ensino, seja porque os pais possuem um certo nível de escolaridade e, por isso, conseguem apoiar seus filhos, seja porque em suas casas há um espaço reservado para os estudos e, em sua maioria, estão em uma situação financeira favorável, ao se comparar com o setor mais pobre da população brasileira.

O fundador do Grupo Sistema Educacional Brasileiro-SEB, Chain Zaher, em entrevista para a Revista Veja, defendeu que os colégios particulares conseguiram se adaptar bem a situação da pandemia, pois foram ágeis ao implementar o ensino remoto, por meio de ferramentas digitais que transmitem conteúdo de qualidade a crianças e jovens. Ele enfatizou ainda que esses jovens possuem acesso à internet com capacidade suficiente de transmitir o material didático (ZAHER, 2020).

Contudo, não se pode deixar de mencionar que as instituições privadas também encontram algumas dificuldades nesse período, como por exemplo, o controle de frequência dos alunos, aplicação dos testes e verificação da aprendizagem.

Porém, não há dúvidas que o grande problema no Brasil, concentra-se, principalmente, no ensino público, seja porque as escolas não possuem os equipamentos necessários para a transmissão de conteúdo, seja porque os alunos não tem acesso aos meios digitais e/ou internet de boa qualidade, seja ainda porque não possuem espaço adequado para o ensino dentro de casa ou ainda porque não podem contar com o auxílio dos pais que, muitas vezes, estão preocupados com o emprego ou, por vezes, estão desempregados.

Esse cenário é extremamente preocupante, pois a formação intelectual da nova geração é, justamente, o meio mais adequado para diminuir as desigualdades sociais. Ademais, o direito a educação deve ser democratizado, conforme previsão legislativa, e qualquer cenário que dificulte o aprendizado ou que limite o direito fundamental, deve ser visto com bastante cautela por todos da sociedade e, principalmente, pelo poder público.

No que diz respeito ao acesso aos meios eletrônicos, uma pesquisa Nacional por Amostra de Domicílios Contínua (PNAD Contínua), de 2018, realizada pelo Instituto 
Brasileiro de Geografia e Estatística (IBGE), investigou no quarto trimestre de 2018, pela terceira vez, o tema suplementar sobre Tecnologia da Informação e Comunicação (TIC) nos aspectos de acesso à Internet e à televisão e posse de telefone móvel celular para uso pessoal. O estudo foi realizado nas Grandes Regiões do Brasil (IBGE, 2020, p. 1).

Por meio da pesquisa, foi possível verificar que 79,1\% dos domicílios brasileiros possuem acesso à internet. Na área urbana, esse número corresponde a 83,8\% dos domicílios e, na área rural, a 49,2\%. O rendimento real médio per capita dos domicílios em que há utilização da Internet $(\mathrm{R} \$ 1.769)$ foi quase o dobro do rendimento dos que não utilizavam esta rede ( $\mathrm{R} \$ 940)$. A grande diferença entre esses dois rendimentos foi observada em todas as Grandes Regiões (IBGE, 2020, p. 6).

A pesquisa ainda revelou que, nas residências brasileiras, o acesso à internet é feito $50,7 \%$ por microcomputador e $12 \%$ por tablet (IBGE, 2020, p. 10). Sabe-se que tais dispositivos são de suma importância para o acesso à internet e, principalmente, para o acesso ao material pedagógico. A pesquisa revelou que uma em cada quatro pessoas no Brasil não tem acesso à internet. Em números totais, isso representa cerca de 46 milhões de brasileiros que não acessam a rede. Número expressivo de brasileiros que ainda não possuem condições de usufruir do ensino a distância (IBGE, 2020, p. 10).

Factível que o uso exclusivo de plataformas digitais tem como consequência a exclusão das camadas mais pobres da sociedade. Marcos Garcia Neira, diretor da FEUSP, defende que, no complexo cenário atual, é impossível definir encaminhamentos didáticos que atendam todas as singularidades, em seus dizeres:

\footnotetext{
Muitos dispõem apenas de seus celulares para conectarem-se. Nem todos possuem condições ou conhecimentos suficientes para operar ferramentas virtuais. Muitos são responsáveis por crianças e idosos. Há pessoas que estão perdendo os meios de subsistência (ADUSP, 2020, on-line).
}

Além disso, esses jovens que não possuem acesso à internet são comumente os que ajudam na renda familiar, conciliando trabalho e estudo.

Importante destacar que, além da dificuldade dos alunos, há, por outro lado, a questão enfrentada pelo Poder Público, pelas secretarias estaduais e municipais, no que diz respeito ao ensino remoto. 
O Centro de Inovação para a Educação Brasileira (CIEB), em parceria com o Conselho Nacional de Secretários de Educação (Consed), a União Nacional dos Dirigentes Municipais de Educação (Undime) e Fundação Lemann realizou uma pesquisa para entender como as secretarias estaduais e municipais se prepararam para se adequar ao ensino remoto, por meio da pesquisa intitulada "Planejamento das Secretarias de Educação do Brasil para ensino remoto" (CIEB, 2020).

O estudo teve respondentes de 3.032 Secretarias de Educação de todo o Brasil, dos quais 3.011 municipais (54,5\% do total nacional) e de 21 secretarias estaduais (77,8\% do total nacional) (CIEB, 2020).

Com o estudo, foi possível verificar que $63 \%$ das redes municipais e $60 \%$ das redes estaduais não adotaram estratégias para o ensino remoto. Além disso, mais de $85 \%$ das secretarias, tanto estaduais quanto municipais, não sabem ainda como farão o registro de presença nem a avaliação de aprendizagem dos estudantes sobre este período. Foi possível verificar também que $40 \%$ das Secretarias Municipais não utilizam recursos tecnológicos (CIEB, 2020).

Mesmo com todas essas dificuldades, há quem defenda que o ensino à distância é a nova realidade e que, em poucos anos, a quantidade de instituições oferecendo Ead será superior àquelas que oferecem ensino presencial. Há ainda quem defenda que a Covid pode estar sendo usada para introduzir o Ead nas instituições de ensino.

\section{O FUTURO DA EDUCAÇÃO NO BRASIL: CONSEQUÊNCIAS ADVINDAS DA PANDEMIA}

O futuro da educação pós-pandemia no Brasil pode parecer incerto; porém, algumas situações já são esperadas e, por isso, é necessário que o país esteja preparado para passar pelos obstáculos que virão.

Primeiro que muitos alunos irão perder o ano letivo de 2020, seja porque a instituição de ensino não conseguiu se adaptar à nova realidade e, dessa feita, não conseguiu oferecer o ensino remoto para seus alunos ou, ainda, porque o próprio aluno não teve condições de fazer um estudo à distância de maneira adequada, por falta de acesso a meios eletrônicos, como tablet, computador ou por não ter acesso a internet. Alguns especialistas defendem que as instituições deverão se preparar de modo extra 
para o retorno as aulas para que as aulas presenciais compensem as defasagens (IDOETA, 2020).

Como visto, a parcela mais pobre da população, provavelmente, será a mais prejudicada. Alguns especialistas defendem que haverá uma alta no número de evasão escolar, em decorrência desse longo período sem aula presencial.

Em matéria veiculada no site da Câmara, por Sílvia Mugnatto, sobre a audiência da Comissão Mista do Congresso que acompanha as ações econômicas de combate à pandemia, o presidente da União Nacional dos Dirigentes Municipais de Educação, Sr. Luiz Miguel Garcia, discute sobre a evasão no ambiente escolar:

\begin{abstract}
O grande esforço que nós fizemos neste período todo é para que a escola continuasse mantendo o vínculo para a gente não ter o risco de uma evasão escolar ainda maior quando terminar o processo de pandemia. Porque nós já temos o aluno que estava fora de aula por alguma razão e a gente trabalha sempre para trazê-lo. E neste momento de pandemia, nós geramos novos excluídos. Aqueles que a escola optou por usar tecnologias digitais e ele não tem condição de ter acesso à internet plena. Aquele que a escola mandou atividades impressas, mas os pais são analfabetos. E nós vamos gerar a possibilidade de ter aqueles que tenham medo. $\mathrm{O}$ medo da volta. $\mathrm{O}$ discurso de que este ano está perdido. Então estamos trabalhando muito forte para dizer que não (MUGNATTO, 2020, on-line).
\end{abstract}

No mesmo sentido, foi a opinião do presidente do Conselho Nacional de Educação (CNE), Luiz Roberto Liza Curi, na audiência da Comissão Mista do Congresso, conforme se verifica na matéria veiculada por Rodrigo Baptista no site do Senado. Ele estima que $30 \%$ das famílias temem que os filhos desistam da escola. Por conta disso, defende que é fundamental pensar em medidas de acolhimento dos estudantes como reaproveitamento de estudos. Em seus dizeres:

Temos também dados que demonstram que $30 \%$ das famílias brasileiras temem que os seus filhos desistam da escola, que não retornem mais. Nós estamos cuidando de acolhê-los nesse momento de forma mais ampla, inclusive colocando a reposição na perspectiva desse acolhimento, na perspectiva do reaproveitamento do que não pôde ter sido aproveitado em determinadas realidades, em determinadas redes, para que também se evite a reprovação, para que haja uma perspectiva de aproveitamento amplo (BAPTISTA, 2020, on-line).

Os estudantes enfrentam dificuldades financeiras em meio à pandemia, fator que estimula a evasão escolar. $\mathrm{Na}$ pesquisa intitulada "Juventude e Pandemia do Coronavírus", realizada em parceria pela Unesco, Conselho Nacional da Juventude 
(Conjur), Aliança em Movimento e Fundação Roberto Marinho, verificou-se que quatro em cada dez participantes indicam ter diminuído ou perdido sua renda pessoal. E, em relação a renda familiar, cinco em cada dez mencionam que suas famílias tiveram redução (CONJUVE, 2020).

Por conta dessa nova realidade, $33 \%$ dos jovens entrevistados precisaram buscar uma nova forma de complementar a renda. Assim, muitas vezes, o estudo deixa de ser prioridade. Ainda segundo dados da pesquisa, três em cada dez jovens disseram que já pensaram em não retornar aos estudos após o fim da pandemia (CONJUVE, 2020).

Especialistas em educação acreditam que estudantes de instituições menos estruturadas, principalmente em regiões carentes, percam a motivação em continuar os estudos e abandonem as aulas presenciais (IDOETA, 2020).

Além da preocupante situação da evasão escolar, estudiosos defendem que a pandemia irá influenciar o comportamento dos alunos e estudantes, já que pode aumentar os casos de ansiedade, medo, depressão e pânico.

Em entrevista para Mateus Salomão, para o jornal Estado de Minas Nacional, a neuropsicóloga Flávia Martins afirma que "Infelizmente o isolamento aumenta a necessidade humana de contato social. Se esse contato não pode existir, muitas pessoas terão um adoecimento" (SALOMÃO, 2020, on-line).

Em relação à educação ela aduz que haverá um impacto tanto para professores, que terão que lidar com a pressão de se adaptarem a novos modelos de ensino e também para os alunos que precisam lidar com a insegurança do momento, em seus dizeres:

O que a gente vai ver é um grande impacto de adoecimento mental em 2021, tanto em professores, com a pressão de adaptar-se a novos modelos de ensino, quanto em crianças e adolescentes pela insegurança que o momento traz (SALOMÃO, 2020, on-line).

Mas, o ponto mais significativo de como ficará a educação pós pandemia, será o aceleramento da mudança do sistema de ensino presencial para o ensino remoto. $\mathrm{O}$ futuro da educação é o ensino à distância.

Isso porque já há uma tendência mercadológica na adoção do Ead, principalmente no ensino superior, pelas instituições particulares. E, são elas que detêm a maior parcela deste mercado. Conforme dados divulgados pelo Inep (órgão do Ministério da educação) no censo da educação Superior de 2018, 88,2\% das instituições 
de ensino superior são privadas em contraste com $11,8 \%$ de instituições públicas (INEP, 2018).

No mesmo estudo, foi possível verificar que o número de vagas ofertadas em cursos universitários à distância, no ano de 2018 - 7,1 milhões - foi maior do que o número de vagas em cursos presenciais - 6,3 milhões (INEP, 2018).

Os educadores defendem que o avanço do Ead foi uma maneira de ganhar escala e baratear os custos das grandes instituições. Essa tese é difundida por Fredric Litto, presidente da Associação Brasileira de Educação à Distância (Abed) e professor emérito da USP em entrevista à BBC, para Paula Adamo Idoeta:

\footnotetext{
Uma boa porcentagem das escolas fez isso para baratear (o ensino) e ganhar mais dinheiro, demitindo, por exemplo, o corpo docente com doutorado, que é mais caro de manter. É bom fugir desse tipo de instituição, porque ela provavelmente não vai investir no enriquecimento de seus cursos e materiais e não vai além (do básico) (IDOETA, 2020, on-line).
}

A Associação Brasileira de Mantenedoras de Ensino Superior (Abmes) projeta que, em 2023, o número de matrículas na modalidade Ead vai superar o ensino presencial no Brasil. De acordo com o estudo, a projeção é de que, em 2023, haja 2.276.774 matrículas novas de ensino superior na educação à distância, o correspondente a $51 \%$ do total, enquanto que os cursos presenciais das instituições particulares registrarão 1.993.319 ingressantes (ABMES, 2018).

Em entrevista à Eduardo Matos para Gaúchazh, a consultora na área de recursos humanos e uma das diretoras da Associação Brasileira de Recursos Humanos no estado do Rio Grande do Sul (ABRH-RS), Laira Correa Seus, afirma: "Não só as instituições de graduação e pós-graduação, mas inclusive a ABRH e outras entidades que realizam cursos profissionalizantes estão investindo no Ead. É um caminho aparentemente sem volta" (MATOS, 2020, on-line).

Em entrevista para Aline Nunes de A Gazeta, Ivan Gontijo, coordenador de projetos de Todos pela educação, observa que o aumento no Ead se deve a uma percepção mercadológica das faculdades de que é mais lucrativo formar a distância: "Em média, o custo é três vezes menor do que o presencial e ainda é possível colocar maior número de alunos para estudar, uma vez que não há limite físico de sala" (NUNES, 2019, on-line). 
Por fim, há ainda os que defendam que a pandemia pode estar sendo usada para introduzir Ead nas universidades com o fim de atender interesses econômicos, em detrimento do ensino de qualidade.

Desse modo, pode-se analisar que já havia um crescimento na oferta de cursos Ead, em comparação com cursos presenciais, acredita-se que o cenário da pandemia veio para acelerar esse processo.

Diante disso, pode-se esperar que o cenário da educação pós-pandemia, seja caracterizado pela alta no número da evasão escolar, pelos impactos psicológicos provocados em alunos e professores e, também, pela mudança no panorama da educação, no que diz respeito a migração do ensino presencial para a educação à distância.

Pois bem, já que o ensino à distância tende a ser o futuro da educação, importante discorrer sobre quais seriam as possíveis consequências da adoção dessa modalidade.

Primeiro fazendo uma comparação entre o modelo presencial e remoto, no que diz respeito a quantidade de alunos que conseguiram se formar no ensino superior. No ano de 2018, dos 2 milhões de alunos que se matricularam em universidades presenciais, apenas, 990 mil conseguiram se formar. E, quando comparado ao ensino à distância, esse número cai ainda mais, para um quinto, pois houve apenas 274 mil alunos formados, em comparação com os 1,3 milhão que se matricularam no mesmo ano (INEP, 2018).

Além disso, especialistas defendem que a metodologia utilizada no ensino a distância não é a mais adequada para o entendimento do conteúdo. Nesse sentido, Arisa Araújo da Luz, pós-doutora em educação menciona, em reportagem para Gaúchazh, que alguns conselhos profissionais ainda rejeitam a oferta de cursos de Ead, pois entendem que a metodologia utilizada não é a mais indicada para a compreensão do conteúdo. Em seus dizeres:

Alcançar a qualidade é difícil. Porque, quando falamos em formação de professores, nós estamos falando em atividades vivenciais. A atividade de professorar se pauta pelo contato, e isso nós não vamos ter em alguns cursos EaD (MATOS, 2020, on-line). 
Portanto, os cursos em Ead retiram justamente o contato entre alunos e professores, o que produz experiências de convivência humana fundamentais para o desenvolvimento da pessoa, em qualquer idade.

O pedagogo e pós-doutor em Sociologia Gregório Grisa, também em entrevista para a Gaúchazh, afirma que "O crescimento marcante do EaD não se dá em instituições de excelência" (MATOS, 2020, on-line). Segundo ele, há uma lógica na redução de gastos e otimização por parte das instituições que oferecem o ensino à distância, mencionando que a qualidade do ensino deve diminuir, conforme trecho abaixo transcrito:

Há uma lógica de redução de gastos, economia e certa otimização de processos por parte dessas instituições que vêm ofertando numa escala cada vez maior de cursos a distância. Infelizmente, a tendência para o futuro é termos registros de cursos um pouco mais precarizados e mais aligeirados. Isso acende uma luz amarela quando à qualidade do ensino (MATOS, 2020, on-line).

Nítido é que o viés mercadológico não pode se sobrepor ao ensino, pois, acima de tudo, deve-se prezar pela qualidade e desenvolvimento socioeconômico da população, o qual virá dentre outros fatores, pela educação de qualidade.

Além disso, dados do Ministério da Educação, de 2017, mostram que apenas $0,5 \%$ dos cursos oferecidos do modo a distância tem nota máxima no indicador de qualidade do governo. Na modalidade presencial, esse percentual é de 2,5\% (MATOS, 2020).

O diretor de políticas educacionais do Todos pela educação, Olavo Nogueira Filho, na entrevista para Gaúchazh se mostra desfavorável ao ensino à distância e afirma:

O crescimento do ensino a distância vai na contramão daquilo que a gente precisaria fazer para enfrentar os desafios da formação de professores. E vai na contramão também daquilo que os países que têm as melhores estruturas de formação de professores fazem (MATOS, 2020, on-line).

Assim, o Ead não pode ser implementado no país se for no sentido de reduzir a qualidade da educação existente, a qual reitera já possui os mais variados problemas que ainda não foram solucionados.

A Organização das Nações Unidas (ONU) produziu um relatório sobre o impacto da pandemia no direito à educação. O relatório faz uma série de recomendações 
para cada contexto local, todas na direção de mitigar o agravamento de desigualdades e discriminações. O documento enfatiza que a implementação da Educação a Distância durante a pandemia deve ser vista apenas como "solução temporária" (CAMPANHA NACIONAL PELO DIREITO À EDUCAÇÃO, 2020).

A relatora especial pelo direito à educação da ONU, Kombou Boly Barry, defende que: "A digitalização da educação nunca deve substituir a educação presencial, e a enorme entrada de atores privados ligados à tecnologia digital deve ser considerada um grande perigo para os sistemas educacionais e ao direito à educação de todos no longo prazo" (CAMPANHA NACIONAL PELO DIREITO À EDUCAÇÃO, 2020, online).

Assim, apesar da forte tendência na implantação do Ead, em detrimento do ensino presencial, ainda mais após o período da pandemia, muitas são as críticas em torno desta modalidade, visto que, na maioria das vezes, tem como intuito baratear custos, reduzindo quadro de professores e sobrepondo direitos econômicos a direitos educacionais.

Pois bem, se o ensino a distância não se mostra o meio mais adequado de acesso à educação, defende-se que a solução, conforme apontado por especialistas, seria a adoção do modelo híbrido de ensino, com vistas a proteger o direito fundamental à educação.

\section{DA NECESSIDADE DE VALORIZAÇÃO DOS PROFISSIONIS DA EDUCAÇÃO E A PROPOSTA EDUCACIONAL DO ENSINO HÍBRIDO}

Resta claro que a presença e o contato fazem parte da natureza humana e estão fazendo grande falta neste contexto de pandemia e não podia ser diferente no ambiente escolar e acadêmico, em que se cria um vínculo entre professores e alunos, o qual nitidamente auxilia no aprendizado e crescimento pessoal do ser humano.

Indiscutível que, apesar de todas as dificuldades no âmbito da educação no Brasil, o ensino presencial ainda é a melhor opção; porém, não se pode olvidar a necessidade de valorização e o devido reconhecimento do profissional da educação, o qual recebe baixos salários em contrapartida a longas jornadas de trabalho, assim como 
normalmente é responsável por uma quantidade exorbitante de alunos e, por isso, não pode exercer de forma plena seu papel de educador.

Portanto, faz-se necessária a valorização do ensino de forma plena e não apenas como instrumento de barganha política, como muito tem se visto no contexto brasileiro, de modo que as escolas e universidades têm papel imprescindível da formação de seres humanos melhores e pensantes em uma sociedade, o que muito contribuirá para o crescimento do país.

Já no que se refere a implantação do ensino Ead, especialistas em educação defendem que adotar o ensino $100 \%$ à distância não é a solução mais adequada para o país. Para eles, uma alternativa seria a adoção do modelo híbrido de ensino. Ou seja, parte da matéria seria ministrada por meios remotos, mas haveria uma parcela do curso que necessariamente deveria ser feita no modo presencial.

Em entrevista para Eduardo Matos, da Gaúchazh, o diretor-executivo do Semesp, entidade que reúne mantenedoras de universidades do Brasil, Rodrigo Capelato, defende que métodos mais consistentes de ensino a distância precisam ser elaborados, em seus dizeres "mais pautados em interatividade e modelos tecnológicos atrativos, além de preservarem atividades presenciais que gerem convivência com o corpo acadêmico" (MATOS, 2020, on-line).

O diretor da Abmes, Sólon Caldas, em reportagem para Gaúchazh, defende que só modelos híbridos podem garantir a qualidade do Ensino Superior, em seus dizeres:

O mundo todo está utilizando a tecnologia na formação de graduandos. E no Brasil não é diferente. É preciso aprimorar o modelo, com o aluno, por exemplo, cursando em EaD toda a parte teórica e fazendo presencialmente na instituição de ensino toda a parte prática (MATOS, 2020, on-line).

Arisa Araújo da Luz, também em reportagem para Gaúchazh, menciona que: “(...) Talvez tenhamos que encontrar uma forma híbrida. Mas, para mim, a formação de professores deve estar no contato, na presença" (MATOS, 2020, on-line).

Defende-se que o ensino presencial ainda é a melhor opção para o contexto vivenciado contemporaneamente, pois traz o convívio, que é intrínseco ao ser humano, que buscou desde os primórdios a vivência em sociedade, e reflete no ambiente escolar e acadêmico aprendizados que vão muito além dos conteúdos didáticos como português, 
matemática ou conteúdos específicos do ensino superior, formando a pessoa humana e um bom cidadão para o seio social.

É assente que nem toda a população tem acesso à internet $\mathrm{e}$ às tecnologias mais modernas, de modo que o ensino remoto escancarou a desigualdade social em todo o país, por isso não se mostra justo que o Ead venha expor ainda mais as desigualdades e deixe a margem aqueles que já são rotineiramente esquecidos pelo Estado.

Assim, a adoção do Ead não seria o mais adequado para o contexto social brasileiro, conforme apontam os especialistas. Nesse sentido, defende-se a adoção do ensino híbrido, de modo a reduzir os custos almejado pelas instituições e, fornecendo, ao mesmo tempo, um ensino de qualidade e acessível a todos, buscando dar efetividade aos valores preconizados pelo Estado democrático de direito e, principalmente, ao direito fundamental à educação.

\section{CONCLUSÃO}

Por meio deste trabalho, foi possível verificar que o direito à educação é um direito fundamental assegurado constitucionalmente, previsto no capítulo dos direitos sociais, em nossa Constituição. Isso deve ser levado em consideração, pois, historicamente, os direitos sociais emergiriam da necessidade de uma atuação positiva por parte do Estado, no sentido de concretizar os direitos sociais.

E, diante do contexto da pandemia, as instituições de ensino e também o Poder Público tiveram que se adaptar e adotar soluções para garantir que os alunos não perdessem o ano letivo, por conta disso, muitas instituições optaram pelo ensino remoto. Com vistas a regularizar esse método de ensino, foram expedidas portarias de caráter temporário pelo Estado.

Percebe-se que, no Brasil, a problemática da oferta do ensino remoto não está atrelada apenas a questão jurídica e/ou técnica. Mas o grande cerne da questão é a desigualdade social que assola o país e que impede o acesso democrático à educação por todos os alunos.

Foi possível analisar também que a tendência pós-pandemia é uma alta na evasão escolar e também que professores e alunos apresentem algum sintoma psicológico como depressão, ansiedade e medo. Além disso, discutiu-se que 
provavelmente esse cenário irá acelerar uma tendência mercadológica de alterar o modelo educacional de ensino presencial para o ensino remoto, o que é criticado por muitos especialistas da educação.

Verifica-se que, conforme estudiosos, a solução do ensino à distância adotado durante a pandemia deve ser temporária e que os interesses econômicos não devem se sobrepor ao direito à educação de qualidade.

Nesse sentido, primeiramente, defende-se a necessidade de maior valorização do profissional da educação, considerando seu papel imprescindível na formação de cidadãos e, quanto ao modelo de ensino a ser adotado, inicialmente, entende-se ser o ensino presencial o mais adequado; porém, considerando a realidade posta, o modelo híbrido de educação seria o mais plausível para manter a qualidade da educação. Desse modo, parte da matéria seria ministrada por meios remotos e a outra parcela, principalmente as aulas práticas, seriam realizadas no modo presencial. Assim, a educação estaria atrelada aos avanços tecnológicos dos dias atuais, mas sem perder a essência da troca nas relações entre alunos e entre alunos e professores, preservando o direito fundamental à educação.

\section{REFERÊNCIAS}

ABMES - Associação Brasileira de Mantenedoras de Ensino Superior. Em 2023, instituições privadas terão mais alunos no ensino à distância que no presencial. Disponível em: <https://abmes.org.br/noticias/detalhe/2789/em-2023-instituicoesprivadas-terao-mais-alunos-no-ensino-a-distancia-que-no-presencial>. Acesso em: 15 ago. 2020.

ADUSP - Associação dos Docentes da Universidade de São Paulo. Não se trata de ser a favor ou contra EaD, diz diretor da Faculdade de Educação: "A mera conversão de disciplinas presenciais em disciplinas a distância trará prejuízos". Disponível em: <https://www.adusp.org.br/index.php/defesauniv/3606-nao-se-trata-de-ser-a-favorou-contra-ead-diz-diretor-da-faculdade-de-educacao-a-mera-conversao-de-disciplinaspresenciais-em-disciplinas-a-distancia-trara-prejuizos>. Acesso em: 18 ago. 2020.

ALEXY, Robert. Direitos fundamentais no estado constitucional democrático (para a relação entre os direitos do homem, direitos fundamentais, democracia e jurisdição constitucional). Tradução Luis Afonso Heck. Revista da Faculdade de Direito da UFRGS. v. 16, 1999, p. 203-214.

BAPTISTA, Rodrigo. Evasão escolar pode aumentar com pandemia, alertam debatedores. Senado Federal. Disponível em: 
$<$ https://www12.senado.leg.br/noticias/materias/2020/07/09/evasao-escolar-podeaumentar-com-pandemia-alertam-debatedores >. Acesso em: 18 ago. 2020.

BOAVENTURA de Sousa Santos. A cruel pedagogia do vírus.1.ed. São Paulo: Boitempo, 2020.

BRASIL. Constituição da República Federativa do Brasil de 1988. Disponível em: http://www.planalto.gov.br/ccivil_03/constituicao/constituicao.htm. Acesso em: 15 ago. 2020.

BRASIL. Lei $\mathbf{n}^{\mathbf{9}}$ 9.394, de 20 de dezembro de 1996. Disponível em: http://www.planalto.gov.br/ccivil_03/leis/19394.htm. Acesso em: 15 ago. 2020.

BRASIL. Portaria $n^{\circ}$ 544, de 6 de julho de 2020. Diário Oficial da União. Disponível em: https://www.in.gov.br/en/web/dou/-/portaria-n-544-de-6-de-julho-de-2020266199471. Acesso em: 15 ago. 2020.

CAMPANHA NACIONAL PELO DIREITO À EDUCAÇÃO. Relatório da ONU sobre o impacto da pandemia no direito à educação incorpora recomendações da Campanha. Disponível em: <https://campanha.org.br/noticias/2020/07/05/relatorio-daonu-sobre-o-impacto-da-pandemia-no-direito-educacao-incorpora-recomendacoes-dacampanha/>. Acesso em: 14 ago. 2020.

CARVALHO, Marco Cesar de. O constitucionalismo no Brasil: uma história de evolução política e social. In: Direitos fundamentais: história, evolução e problemas atuais: estudos em comemoração aos 10 anos do curso de direito da Libertas. CARVALHO, Marco Cesar de; Cia, Michele (orgs.). Passos MG: Gráfica e Editora São Paulo, 2015, p. 242-243.

CERIONI, Clara. Desigualdade e alfabetização desafiam educação na pandemia da covid-19. Exame. 2020. Disponível em: < https://exame.com/brasil/homeschoolingalfabetizacao-e-os-desafios-da-educacao-na-pandemia/>. Acesso em: 18 ago. 2020.

CIEB - Centro de Inovação para a educação Brasileira. Pesquisa analisa estratégias de ensino remoto de Secretarias de Educação durante a crise da Covid-19. 2020. Disponível: <https://cieb.net.br/pesquisa-analisa-estrategias-de-ensino-remoto-desecretarias-de-educacao-durante-a-crise-da-covid-19/>. Acesso em: 18 ago. 2020.

CONJUVE - Conselho Nacional da Juventude. Pesquisa Juventudes e Pandemia do Coronavírus. 2020. Disponível em: <https://4fald1bc-0675-4684-8ee9031db9be0aab.filesusr.com/ugd/f0d618_41b201dbab994b44b00aabca41f971bb.pdf>. Acesso em: 18 ago. 2020.

FERREIRA FILHO, Manoel Gonçalves. Direitos humanos fundamentais. São Paulo: Saraiva, 2011.

IBGE. Acesso à Internet e à televisão e posse de telefone móvel celular para uso pessoal 2018. Pesquisa Nacional por Amostra de Domicílios Contínua. Disponível em: 
<https://biblioteca.ibge.gov.br/visualizacao/livros/liv101705_informativo.pdf >. Acesso em: 18 ago. 2020.

IDOETA, Paula Adamo. Os desafios e potenciais da educação à distância, adotada às pressas em meio à quarentena. BBC News Brasil. 2020. Disponível em: <https://www.bbc.com/portuguese/brasil-52208723>. Acesso em: 10 ago. 2020.

INSTITUTO NACIONAL DE ESTUDOS E PESQUISAS EDUCACIONAIS ANÍSIO TEIXEIRA. Censo da Educação Superior 2018 Notas estatísticas. Brasília-DF. 2019 Disponível em: http://download.inep.gov.br/educacao_superior/censo_superior/documentos/2019/censo _da_educacao_superior_2018-notas_estatisticas.pdf>. Acesso em: 14 ago. 2020.

JOLIE, Angelina; AZOULAY Audrey, Closing Schools Has Derailed the Lives of Kids All Over the World. Here's How We Can Help Them Keep Learning. Time. 2020. Acesso em <https://time.com/5810017/coronavirus-school-closings-educationunesco/>. Acesso em: 12 ago. 2020.

LEITE, Carlos Henrique Bezerra. Eficácia dos direitos fundamentais na relação de emprego. Revista Síntese Trabalhista e Previdenciária. São Paulo, v. 22, p. 58-70, maio, 2011.

MARMELSTEIN, George. Curso de Direitos Fundamentais. 3. ed. São Paulo: Atlas, 2011.

MATOS, Eduardo. Especialistas são cautelosos a avaliar ensino a distância. Gaúchazh. Educação e trabalho. Disponível em: <https://gauchazh.clicrbs.com.br/educacao-eemprego/noticia/2020/01/especialistas-sao-cautelosos-ao-avaliar-ensino-a-distanciack4u857ti01lu01nv2f6cnjbf.html>. Acesso em: 11 ago. 2020.

MUGNATTO, Sílvia. Autoridades educacionais estão preocupadas com evasão escolar pós-pandemia. Câmara dos Deputados. Disponível em: <https://www.camara.leg.br/noticias/674951-autoridades-educacionais-estaopreocupadas-com-evasao-escolar-pos-pandemia/>. Acesso em: 18 ago. 2020.

NUNES, Aline. Educação a distância cresce, mas qualidade não acompanha. A Gazeta. 2020. Disponível em: <https://www.agazeta.com.br/es/gv/educacao-a-distancia-crescemas-qualidade-nao-acompanha-0919/>. Acesso em: 13 ago. 2020.

SALOMÃO, Mateus. COVID-19: Estudantes devem voltar às salas de aula com traumas e danos psicológicos. Jornal Estado de Minas. Disponível em: $<$ https://www.em.com.br/app/noticia/nacional/2020/08/05/interna_nacional,1173258/co vid-19-alunos-devem-voltar-sala-de-aula-traumas-e-dano-psicologico.shtml $>$. Acesso em: 18 ago. 2020.

SILVA, José Afonso da. Curso de Direito Constitucional Positivo. 32. ed. São Paulo: Malheiros, 2009. 
TAVARES, André Ramos. Direito Fundamental à Educação. Ânima: Revista Eletrônica do Curso de Direito da Opet, v. 1. 2009. p. 21-41. <http://www.animaopet.com.br/pdf/anima1/artigo_Andre_Ramos_Tavares_direito_fund.pdf $>$. Acesso em: 12 ago. 2020.

ZAHER, Chain. Artigo: O vírus da desigualdade na educação. Revista Veja. 2020. $<$ https://veja.abril.com.br/educacao/artigo-o-virus-da-desigualdade-na-educacao/>.

Acesso em: 12 ago. 2020. 